\title{
Strengthening College Students' Integrative Leadership Orientation by Building a Foundation for Civic Engagement and Multicultural Competence
}

\author{
Krista Soria, $\mathrm{PhD}$ \\ Analyst \\ Office of Institutional Research \\ University of Minnesota \\ 272-4 McNamara Alumni Center Building \\ 200 Oak St. SE \\ Minneapolis, MN 55455 \\ ksoria@umn.edu \\ Seth Snyder \\ University of Minnesota \\ snyde592@umn.edu \\ Alex P.Reinhard \\ University of Minnesota \\ rein0222@umn.edu
}

\begin{abstract}
Integrative leadership theories are thriving in the literature, yet very few studies have explored individual characteristics of integrative leadership and conditions that may promote individuals' integrative leadership orientation. In particular, little is known about the factors that may promote undergraduate college students' development of an orientation toward integrative leadership, although many colleges and universities are charged with developing future leaders to tackle grand societal challenges. The purpose of this study was to examine higher education institutions' contributions to college students' civic engagement and multicultural competence as well as the relationships between these contributions and students' development of an integrative leadership orientation. Using a multi-institutional survey of college seniors $(n=5,922)$, the results of this study suggest institutional efforts to develop students' multicultural competence and civic engagement are positively associated with undergraduate students' development of an integrative leadership orientation.
\end{abstract}

\section{Introduction}

As multi-faceted challenges continue to capture our collective attention-including poverty, oppression, social injustice, global health concerns, and environmental sustainabilitynew leadership is needed to navigate these complex and persistent societal and global concerns (Sun \& Anderson, 2012). Given higher education's historical legacy of developing leadership capacity among younger generations, colleges and universities are increasingly viewed as a key source of prospective social change agents to respond to these pressing community needs (Astin \& Astin, 2000). King (1997) noted that some of the most trying but important goals of higher education administrators, faculty, and staff include fostering undergraduate students' development of integrity and strength of character to prepare them for future leadership. In 
response, many colleges and universities have prioritized college students' leadership development, as evidenced by the expansion of both co-curricular and curricular leadership educational programs (Dugan \& Komives, 2007; Soria, Nobbe, \& Fink, 2013; Soria, Fink, Lepkowski, \& Snyder, 2013).

The challenges of the twenty-first century require new ways of approaching problem solving that incorporate not only adaptive, forward-thinking leadership (Heifetz, Grashow, \& Linsky, 2009), but also integrative leadership — the ability to bring diverse groups and organizations together to resolve complex problems and elicit lasting social change (Crosby \& Bryson, 2010). Through teamwork, collaboration, and networking, integrative leadership emphasizes shared power, representing a shift from traditional theories focused on positional leadership, which relies upon hierarchical authority. Integrative leadership correspondingly eschews traditional leadership theories about leader-follower relationships (Sun \& Anderson, 2012). In today's communities, collaboration through civic engagement creates special demands for integrative leadership, because stakeholders with differing levels of multicultural competencies must work together, creating substantial collective action challenges (Page, 2010). In order to prepare effective leaders who can develop collaborations across multiple diverse groups of people, colleges and universities need to create institutional environments that nurture the development of integrative leadership values and principles within their future graduates.

In this study, we examined institutional contributions to college students' development of an integrative leadership orientation. In particular, our goal in this study is to explore whether higher education institutions' contributions to college students' civic engagement and multicultural competence are associated with college students' growth in their integrative leadership orientation.

\section{Integrative Leadership Characteristics and Behaviors}

Amid the ever-expanding body of literature on integrative leadership, researchers have seldom documented the actual competencies, behaviors, and skills that constitute integrative leadership (Silvia \& McQuire, 2010). Williams (2002) constructed a framework of competencybased variables that influenced collaboration, including building effective personal relationships, managing non-hierarchical decision environments through negotiation and brokering, connecting problems and solutions, and mobilizing resources and effort. Similarly, Crosby and Bryson (2005) characterized leadership capabilities necessary for solving societal problems, including an understanding of social and political context, building work groups, communicating and sharing a vision, and effectively implementing policy decisions, among others. This vision of desired public and community-based leadership requires students to gain not only an appreciation for the inherent values of the public domain, but also the skills necessary to work with an increasingly diverse society (Abowitz, Jayanandhan, \& Woiteshek, 2011). Additionally, Morse (2010) suggested that an ideal integrative public leader would be transparent in his or her decision making; possess equality and justice as core values that are also displayed in his or her behaviors; possess the capacity to objectively analyze data and situations without being defensive; hold the common purpose of the collaboration above the narrow interests of his or her own organization; and positively model behaviors that encourage authenticity in others. All of these traits point to a desired shift toward a new conception of leadership more focused on service and action for the common good than the accomplishments of an individual in a leadership role (Gibson \& Longo, 2011). 
Van Wart (2008) organized leadership behaviors into three domains: task-oriented, people-oriented, and organization-oriented. Task-oriented behaviors include actions related to clarifying roles and objectives, delegating and problem solving, managing innovation, and monitoring and assessing work. People-oriented behaviors include developing staff, motivating and managing teams, consulting personnel, and managing conflict or personnel change. Finally, organization-related behaviors include articulating the mission and vision of the organization, strategic planning, managing budgets or human resources, networking and partnering, and managing organizational change. Silvia and McGuire (2010) extended the work of Van Wart (2008) and conducted a large survey of emergency managers in both collaborative and single agency settings. Their findings suggested that integrative leaders "approach network members as equals, share information across the network, share leadership roles, create trust, and [are] mindful of the external environment to identify resources and stakeholders" (Silvia \& McGuire, 2010, p. 275).

While those prior studies examined leaders who were typically well-established in their careers and had likely developed a wide variety of organizational and personal networks, these theories and principles of integrative leadership are less easily applied to a traditional college student population given that many undergraduate students do not have the benefit of career experience. As a consequence, in this paper we examine college students' development of an orientation toward integrative leadership values and perspectives, defined in this paper as a fusion of students' leadership skills, their ability to work within teams and consider multiple perspectives, and their adaptability toward change while remaining focused on larger goals. We hypothesize that college students with a greater integrative leadership orientation may be better positioned to serve as boundary-spanners (Williams, 2002)_individuals who possess the ability to bring diverse organizations together, promote collaboration, and integrate different perspectives and ideas into one common purpose to effect positive social change (Morse, 2010).

Civic Engagement, Diversity, and Multiculturalism in Higher Education

As we explore institutional factors that may be associated with college students' development of an orientation toward integrative leadership, we draw our attention toward two particular constructs important in the missions of many higher education institutions: civic engagement and multicultural competence. Although colleges and universities are ideal settings within which college students can learn more about — and begin to exercise - civic engagement and civic responsibility, become exposed to higher levels of diversity, and develop an orientation toward integrative leadership, scholarship connecting these ideas is relatively sparse. In general, scholarship exploring the influence of higher education on college students' integrative leadership orientation is limited (Dugan \& Komives, 2007). Yet, as our society continues diversifying at increasing rates, preparing college students to become active participants and competent leaders in our pluralistic society becomes even more urgent (Abowitz et al., 2011; Zuniga, Williams, \& Berger, 2005).

Scholars have begun to identify connections between college students' civic engagement, diversity experiences, and development of socially responsible leadership. Based on the social change model (Astin, 1996), socially responsible leadership is defined as a "purposeful, collaborative, values-based process that results in positive social change" (Komives, Wagner, \& Associates, 2009, p. xii). Socially responsible leadership is connected with integrative leadership in that both frameworks value collaboration and societal change; however, socially responsible 
leadership research also focuses on personal development as well as organizational impact (Astin \& Astin, 2000).

Scholars exploring predictors of socially responsible leadership have found interesting connections between civic and community engagement and leadership development; for example, Soria, Nobbe, and Fink (2013) discovered that college students who participated in community service reported greater levels of socially responsible leadership. Similarly, Dugan and Komives (2010) discovered that participation in community service was positively associated with several elements of college students' socially responsible leadership. While those models focus on community service participation, rather than civic engagement (which implies more focused political and civic action), Zimmerman-Oster and Burkhardt (1999) suggested that many higher education leadership programs include civic responsibility and engagement as desired results, with civic, social, and political awareness, civic and political efficacy, and civic and political activity ranked among the top outcomes. Mitchell (2008) continued this trend in a discussion of the ways in which critical service learning develops social justice aims through building authentic community-student relationships. While civic engagement in its many forms has been identified as an outcome of leadership development programs, recent studies have just begun to explore more deeply the college's contribution to students' civic engagement and whether this contribution, in turn, influences students' development of leadership (Mitchell, Keene \& Battistoni, 2011).

Similarly, several studies have examined the benefits of college students' engagement with diversity and their development of leadership capacity; for example, the results of several studies suggest positive relationships between the frequency in which students have participated in sociocultural discussions with their peers and elements of socially responsible leadership (Dugan \& Komives, 2010; Soria, Nobbe, \& Fink, 2013). Scholars who have focused on the broader impact of diversity initiatives, structural diversity, and diverse interactions have discovered positive impacts on students' openness to diversity (Whitt, Edison, Pascarella, Terenzini, \& Nora, 2001); leadership development and cultural knowledge (Antonio, 2001; Soria \& Johnson, 2013); acceptance of diversity, leadership development, and cultural awareness (Hurtado, 2001); intellectual engagement, racial/cultural engagement, citizenship engagement, and active learning (Gurin, Dey, Hurtado, \& Gurin, 2002); and social action engagement (Hurtado, Engberg, \& Ponjuan, 2003).

\section{Conceptual Framework}

Building upon prior research, this study examines whether higher education institutions' contributions to college students' civic engagement and multicultural competence are associated with students' development of integrative leadership potential. The conceptual framework for this study is built upon Astin's (1993) well-established Input-Environment-Output model, which hypothesizes that the background characteristics of college students (inputs) and relevant aspects of the college experience (environment) influence outcomes. As a consequence, controls for inputs (e.g., students' sex, parental education, and racial/ethnic identity), additional academic factors (e.g., grade point average, academic majors, and contributions of general education coursework), and colleges' contributions to students' multicultural competence and civic engagement were entered in separate blocks in a hierarchical regression model predicting students' integrative leadership orientation. 


\section{Method}

\section{Instrument}

Survey data were collected from the ACT College Outcomes Survey, which was administered to college seniors at 15 public higher education institutions from 2000 to 2011. The instrument is comprehensive and asks students questions about their institutions' contributions to a variety of outcomes (e.g., interacting well with people from cultures other than my own) and their personal growth in a variety of outcomes (e.g., learning to be adaptable, tolerant, and willing to negotiate), among many other areas. Data were provided by ACT staff for use in the analyses.

\section{Sample}

At each of the 15 institutions in the sample, the entire population of college seniors were administered the survey, whether electronically, in class, via campus mail, by individual interviews, by U.S. mail, or by a combination of those means. The entire student population (freshmen through seniors) for the participating institutions ranged from 3,560 to 34,480. The majority of institutions in the sample granted masters degrees as the highest degree $(72.2 \%)$, with the remaining $21.9 \%$ granting doctoral degrees and $6.0 \%$ granting only baccalaureate degrees. The institutional response rates varied, ranging from $15 \%$ to $100 \%$, although the average response rate for enrolled seniors across all institutions was $64.4 \%(n=5,922)$. The sample was $56.3 \%$ female $(n=3,331), 2.3 \%$ American Indian or Alaska Native $(n=135), 6.1 \%$ Hispanic or Latino $(n=359), 4.9 \%$ Black $(n=290), 3.9 \%$ Asian or Pacific Islander $(n=228), 83.0 \%$ White $(n=4,917), 2.7 \%$ multiracial $(n=158)$, and $2.1 \%$ other or unknown race $(n=125)$. We selected only the responses from college seniors for this analysis because they were most likely to have experienced several full years enrolled at their respective institutions and were therefore an ideal group for which to analyze both development and the contributions of their institutions.

\section{Measures}

Block one. Variables entered in the first block included students' pre-college characteristics: sex, race or ethnicity, grade point average, and status as a first-generation student, items which were all self-reported by students on the survey. Students were considered first-generation if their parents had not earned a bachelor's degree.

Block two. This block effectively represents many aspects of students' academic experiences on campus, including academic major, contributions of general education coursework on development, and grade point average. Due to the wide variety of academic majors, areas of study were recoded according to larger program categories provided by ACT (2010). For example, agriculture majors included food sciences and technology; natural resources management; agricultural business, economics, mechanics, and production; animal sciences, and others. Home economics and trades majors included childcare development and guidance, culinary arts, textiles and clothing, automotive repair, aircraft mechanics, welding and drafting, fashion design, and others. Sciences majors included astronomy, biology, chemistry, ecology, geology, and others. For each of the larger program categories, anywhere from 10 to 20 different majors were included. 
Students self-reported their grade point average (scaled $1=$ Below D [0.00 to 1.00$]$ to $6=$ A- to A [3.50 to 4.00]). Finally, to estimate the effects of non-major-related coursework on students' development, students were asked to indicate their agreement with two items regarding whether the required courses outside of their major helped them to develop as a whole person and to broaden their awareness of diversity among people, their values, and their cultures. These items were scaled 1 (strongly disagree) to 5 (strongly agree).

Block three. One of the two primary independent variables — civic engagement — was a variable constructed from five survey items that asked students to rate the extent of their colleges' contribution (i.e., students' college experience both in and outside of classes) to their personal growth in four areas (e.g., becoming more aware of local and national political and social issues, recognizing my rights, responsibilities, and privileges as a citizen, etc.) (Table 1). Students could rate the extent of their colleges' contribution on a scale from 1 (none) to 5 (very great).

The second primary independent variable - multicultural competence-was a variable constructed from five survey items that asked students to rate the extent of their colleges' contribution (i.e., students' college experience both in and outside of classes) to their personal growth in four areas (e.g., interacting well with people from cultures other than my own, becoming a more effective member in a multicultural society, etc.) (Table 1). Students could rate the extent of their colleges' contribution on a scale from 1 (none) to 5 (very great).

Dependent measure. The dependent measure in the analysis - college students' growth in an integrative leadership orientation - was a variable constructed from several survey items that asked students to rate their personal growth in six areas (e.g., developing leadership skills, becoming an effective team or group member, learning to be adaptable, tolerant, and willing to negotiate). Students could rate the level of their growth on a scale from 1 (none) to 5 (very much). Together, these items were conceptualized to represent students' orientation toward integrative leadership, as they reflect students' adaptability, willingness to consider opposing points of view, stamina to persist with project completion, and effectiveness as team members. 
Table 1: Summary of Factor Analysis Results for the ACT College Outcomes Questionnaire $(n=5,922)$

\begin{tabular}{|c|c|c|c|}
\hline Item & $\begin{array}{l}\text { Integrative } \\
\text { Leadership } \\
\text { Orientation }\end{array}$ & $\begin{array}{c}\text { Multicultural } \\
\text { Competence }\end{array}$ & $\begin{array}{c}\text { Civic } \\
\text { Engagement }\end{array}$ \\
\hline Developing leadership skills & 0.806 & & \\
\hline Becoming an effective team or group member & 0.795 & & \\
\hline $\begin{array}{l}\text { Becoming more willing to consider opposing } \\
\text { points of view }\end{array}$ & 0.783 & & \\
\hline $\begin{array}{l}\text { Learning to be adaptable, tolerant, and willing } \\
\text { to negotiate }\end{array}$ & 0.777 & & \\
\hline $\begin{array}{l}\text { Becoming more willing to change and learn } \\
\text { new things }\end{array}$ & 0.755 & & \\
\hline $\begin{array}{l}\text { Improving my ability to stay with projects until } \\
\text { they are finished }\end{array}$ & 0.711 & & \\
\hline $\begin{array}{l}\text { Interacting well with people from cultures other } \\
\text { than my own }\end{array}$ & & 0.891 & \\
\hline Dealing fairly with a wide range of people & & 0.853 & \\
\hline Improving my ability to relate to others & & 0.805 & \\
\hline $\begin{array}{l}\text { Developing productive work relationships with } \\
\text { both men and women }\end{array}$ & & 0.752 & \\
\hline $\begin{array}{l}\text { Becoming a more effective member in a } \\
\text { multicultural society }\end{array}$ & & 0.693 & \\
\hline $\begin{array}{l}\text { Preparing myself to participate effectively in } \\
\text { the electoral process }\end{array}$ & & & 0.975 \\
\hline $\begin{array}{l}\text { Becoming more aware of local, national, } \\
\text { political, and social issues }\end{array}$ & & & 0.940 \\
\hline $\begin{array}{l}\text { Recognizing my rights, responsibilities, and } \\
\text { privileges as a citizen }\end{array}$ & & & 0.793 \\
\hline $\begin{array}{l}\text { Becoming sensitive to moral injustices and } \\
\text { ways of avoiding or correcting them }\end{array}$ & & & 0.643 \\
\hline $\begin{array}{l}\text { Actively participating in volunteer work to } \\
\text { support worthwhile causes }\end{array}$ & & & 0.466 \\
\hline Range & -4.501 to 1.673 & -3.088 to 2.108 & -2.381 to 2.087 \\
\hline
\end{tabular}




\section{Data Analysis}

We conducted a factor analysis on 16 items with oblique rotation (promax). Given the large sample size, Kaiser's criteria components, and the convergence of a scree plot that showed inflexions justifying the retention of three components, the final analysis retained the following factors: students' growth in an integrative leadership orientation, civic engagement, and multicultural competence. Table 1 shows the factor loadings after rotation in a pattern matrix, with factor loadings over .40 in bold. Each component had a high reliability: integrative leadership orientation $(\alpha=.87)$, multicultural competence $(\alpha=.87)$, and civic engagement $(\alpha=$ $.85)$. The factor scores were computed using the regression method and saved as standardized scores with a mean of zero and a standard deviation of one.

Following the computation of factor scores, a hierarchical least squares regression predicting students' integrative leadership orientation was run and all variables were entered in three separate blocks into the regression. In the regression, assumptions of multicollinearity, homoscedasticity, linearity, and independent/normal errors were examined. Multicollinearity assumptions were not violated and, in testing homoscedasticity, we detected random scatter and variability in scatterplots of standardized residuals against the standardized predicted values. In producing histograms of standardized residuals and normal probability plots comparing the distribution of standardized residuals to a normal distribution, no evidence for skewness was detected. Examinations of matrix scatterplots suggested the relationships between the predictor and outcome variables were relatively linear. Finally, the residual errors were independent across the model.

\section{Results}

Results from the hierarchical regression analyses predicting students' growth in their integrative leadership orientation suggested that students' pre-college demographic characteristics explained $1.6 \%$ of the variance in students' integrative leadership orientation (Table 2). The second block — which included students' grade point average, academic major, and non-major courses' contribution to their development-explained $13.2 \%$ of the variance in students' integrative leadership orientation. Finally, the third block containing colleges' contributions to students' multicultural competence and civic engagement explained $20.3 \%$ of the variance in students' growth in their integrative leadership orientation.

Several pre-college demographic factors were significant in the regression model. Compared to males, females reported significantly $(p<.01)$ greater growth in their integrative leadership orientation. Hispanic, Latino, and Black students also reported significantly greater growth in their integrative leadership orientation compared to other racial groups. Compared with non-first-generation students, first-generation students reported significantly less growth in their integrative leadership orientation.

The results of the analysis also suggest that some academic factors were significant in the model; for example, students who were admitted to community and personal majors (e.g., criminal justice or law enforcement, social work, public administration and affairs, parks and recreation, etc.) reported significantly lower growth in their integrative leadership orientation compared to students in all other degree programs. In addition, the contributions of students' general education courses to their holistic development and diversity awareness were positively 
associated with their integrative leadership orientation.

The results from the third block of the regression suggest that colleges' contribution to students' multicultural competence and civic engagement was positively associated with students' integrative leadership orientation (Table 2). In other words, college students who reported that their colleges had a greater impact on their ability to interact well with people from different cultures, deal fairly with - and relate to - a wide range of people, and become an effective member of a multicultural society were more likely to report greater personal growth in possessing an integrative leadership orientation. Additionally, students who reported that their colleges contributed more greatly to their ability to prepare for participation in electoral processes, recognize their responsibilities as citizens, become more aware of pressing societal issues, and serve as active volunteers were more likely to report greater personal growth in their integrative leadership orientation.

Examinations of the standardized coefficients suggest that colleges' contribution to students' multicultural competence $(\beta=.429)$ and students' civic engagement $(\beta=.105)$ were some of the most important predictors in the model. The results also suggest that the institutional contributions to students' multicultural competence and civic engagement explained more variance in students' development of an integrative leadership orientation than students' precollege demographic characteristics and students' academic experiences.

Table 2

Regression Analysis Predicting Students' Growth in an Integrative Leadership Orientation

\begin{tabular}{llllll}
\hline & Variable & B & SE & $\beta$ & $p$ \\
\hline (Constant) & & -.749 & .089 & & $* * *$
\end{tabular}

Student Background Characteristics

Female

Hispanic or Latino

American Indian or Alaskan Native

Asian American or Pacific Islander

Black

Multiracial

Other or Unknown Race/Ethnicity

First-Generation

$R^{2}$

$\begin{array}{rrrr}.065 & .024 & .034 & * * \\ .123 & .055 & .029 & * \\ -.012 & .073 & -.002 & \\ -.077 & .057 & -.015 & \\ .192 & .052 & .042 & * * * \\ .035 & .071 & .006 & \\ -.077 & .083 & -.011 & \\ -.045 & .022 & -.023 & * \\ & & .016 & * * *\end{array}$


Academic Experiences

Agriculture majors

Engineering and architecture majors

Education majors

Business and marketing majors

Communications majors

Computer and information sciences majors

Community and personnel majors

Cross-disciplinary majors

Health sciences majors

Home economics and trades majors

Letters, humanities, and languages majors

Sciences majors

Social sciences majors

Non-major course contributions toward holistic development

Non-major course contributions toward diversity awareness

Grade point average

$R^{2}$ change

Institutional Contributions to Development

Multicultural competence

Civic engagement

$R^{2}$ change

Final $R^{2}$

F $\begin{array}{lll}-.135 & .101 \quad-.017\end{array}$

$\begin{array}{lll}.017 & .061 \quad-.009\end{array}$

$\begin{array}{lll}.020 & .049 \quad-.002\end{array}$

$.048 \quad .047 \quad .012$

$.053 \quad .061 \quad .008$

$\begin{array}{lll}-.128 & .075 \quad-.022\end{array}$

$\begin{array}{lll}-.124 & .055 & -.040\end{array}$

$* *$

$\begin{array}{lll}-.190 & .102 \quad-.021\end{array}$

$\begin{array}{lll}.001 & .055 \quad-.007\end{array}$

$\begin{array}{lll}-.034 & .025 & -.005\end{array}$

$.020 \quad .072 \quad-.004$

$\begin{array}{lll}-.039 & .060 & -.017\end{array}$

$\begin{array}{lll}-.019 & .051 \quad-.017\end{array}$

$.088 \quad .014 \quad .064$

$* * *$

$\begin{array}{llll}.076 & .014 & .068 \quad * * *\end{array}$

$.024 \quad .012 \quad .014$

$.132 \quad * * *$

\begin{tabular}{|c|c|c|c|}
\hline .435 & .016 & .429 & $* *$ \\
\hline .105 & \multirow[t]{4}{*}{.015} & .105 & $* *$ \\
\hline & & .203 & $* *$ \\
\hline & & .351 & $* *$ \\
\hline & & 0.123 & $* *$ \\
\hline
\end{tabular}

Note. ${ }^{*} p<.05 ; * * p<.01 ; * * * p<.001$ 


\section{Discussion and Recommendations}

Overall, the results suggest that college students who reported that their colleges contributed more greatly to their multicultural competence and civic engagement also reported greater development in their integrative leadership orientation. College and universities seeking to develop future leaders who are effective team members, adaptable and willing to negotiate, considerate of opposing points of view, and capable of seeing projects to completion may find success in achieving those outcomes by building students' ability to work with others from diverse backgrounds and enhancing their ability to participate as active citizens for the benefit of the nation.

There are likely several ways in which colleges and universities positively contributed to students' development of multicultural competence - and, in turn, several ways in which multicultural competence helped college students to develop a greater integrative leadership orientation. First, college students may have been exposed to structural diversity - the numerical representation of students from diverse identities on campus - which increases the probability that students will encounter others from diverse backgrounds (Gurin, Dey, Hurtado, \& Gurin, 2002). Students may have also engaged in informal interactional diversity, which involves the frequency and quality of intergroup interaction through informal discussions, social activities, or other interactions with students on campus (Gurin et al., 2002). Finally, students could have gained diversity experience through classroom diversity, which includes both learning about diverse groups of people and learning from diverse peers in the classroom (Gurin et al., 2002); for example, students in the sample who perceived that their non-major coursework contributed to their development of diversity awareness were also more likely to report development of their integrative leadership orientation. These diversity experiences may have contributed to students' multicultural competence in a variety of ways, although Gurin et al. (2002) contended that structural diversity is likely the least impactful of the three. It is hypothesized that these diverse interactions lead to multicultural competence, which in turn increased students' orientation toward working as effective team members, considering alternate perspectives, and become more open to change - all characteristics of integrative leadership.

Additionally, there are likely several ways in which the colleges and universities in this sample may have contributed to students' civic engagement - and some connections that can be drawn between students' diversity experiences and their civic engagement as well. Colby, Ehrlich, Beaumont, and Stephens (2003) suggested that colleges and universities can engage students in several student-centered pedagogies that are particularly important in civic education, including service-learning (i.e., connecting service to classroom learning), experiential education (e.g., action research, internships), problem-based learning (i.e., learning centered around concrete, real-world problems), and collaborative learning (i.e., students working together in teams or projects). Students who are engaged in these types of problem-solving learning experiences can reap the benefits of enhanced civic responsibility and purposeful engagement in civic activities that endure beyond graduation and result in the potential solution of communitycentered problems (Hartley \& Harkavy, 2011). Additionally, several studies have linked formal diversity courses with civic and multicultural outcomes. For example, scholars have discovered that students who enrolled in an ethnic or women's studies course demonstrate increased predicted positive civic outcomes including racial understanding (Gurin, 1999) and motivation to promote inclusion and social justice (Zuniga, Williams, \& Berger, 2005). Consequently, the 
interplay between the ways in which colleges and universities contribute to students' diversity experiences and civic engagement can reflect potentially powerful opportunities for students to develop integrative leadership orientations.

We found it interesting that students enrolled in community-oriented majors were significantly less likely than their peers to experience growth in an orientation to integrative leadership. Within our sample, the majority of students pursuing these majors were enrolled in criminal justice, parks and recreation, and social work majors. These results appear to be somewhat incongruous with what might be expected among students who are pursuing community-related degrees; consequently, we recommend scholars explore these findings in greater depth in future research.

The results of this study point toward several concrete steps that colleges and universities can take to spur the development of students' integrative leadership orientation. First, colleges and universities can enhance students' civic engagement by providing multiple opportunities for students to engage in community service and service learning in a variety of contexts (Mitchell et al., 2011). Faculty and staff can encourage students to recognize their responsibilities as participants in a diverse democracy - including advocating for social justice, voting in elections, and volunteering to support various causes. These themes can be embedded within classroom conversations and serve as the focus for general education courses - thereby increasing the likelihood that a wide variety of students will be exposed to themes of civic engagement and diversity regardless of their academic major.

Furthermore, colleges and universities can actively develop students' multicultural competence by supporting students' informal interactions with their diverse peers. Hurtado (2007) found that students who reported positive, informal interactions with diverse peers had higher scores on democratic sensibilities, including their pluralistic orientation and concern for the public good. Conversely, students who had negative interactions with their diverse peers were least skilled in intergroup relations and least likely to develop behaviors to function effectively in a diverse democracy. Positive informal conversations with diverse peers can occur in a variety of institutional contexts, including housing and residential life, on-campus student employment, leadership experiences, and co-curricular involvement.

Finally, leadership development programs on campus can be leveraged to build students' integrative leadership orientation. The signature pedagogies informing leadership educationclass discussion, small group discussions, group projects, research projects, team building, and service learning, among others (Jenkins, 2012) — can also increase the opportunity for students to interact with their diverse peers. Public and community-based leadership education should contain student-centered experiential learning and research-grounded continuous program development, while keeping student participants engaged in sustaining and building the learning community (Abowitz et al., 2011). Broadly speaking, leadership education should enhance students' ability to "transcend individual interests and function in a way that sees the systemic implications of actions that are inextricably connected to others around the globe" (Fincher \& Shalka, 2009, p. 232). Recent leadership development models embrace the deconstruction of leadership as a function of a positional role and view leadership development as a relational process (Gibson \& Longo, 2011; Komives, Lucas, \& McMahon, 2006). These new models seek to promote ways to prepare college students to value the richness of seeking multiple perspectives when resolving social problems and convey the importance of being able to 
"grapple with the new and unscripted problems they can expect to find in every sphere of life" (Schneider, 2005, p. 66). The results of the present study and other research suggest the integration of diversity, multiculturalism, civic engagement, and community service into these leadership education and development programs may result in an increased integrative leadership orientation among college students who participate.

\section{Limitations and Future Directions}

This study examined correlations between students' perceived development of leadership skills and their perceptions of their colleges' contributions to their civic engagement and multicultural competence. Due to limitations in the survey instrument, it was not possible to determine the means through which these higher education institutions contributed to students' development in those key areas (e.g., diversity discussions, diversity in the student body, civic and community engagement opportunities provided by the colleges, etc.). Additionally, limitations in the survey instrument also constrict the definition of integrative leadership in this study - while it is possible to perceive students' orientation toward integrative leadership, little is known about the extent to which students actually engaged in collaborative work or may engage in collaborative leadership efforts in the future. Finally, limitations in the data set prevented a deeper understanding of the colleges and universities that comprised the sample. For example, some institutions in the sample may have more centrally featured diversity, multiculturalism, and civic/community engagement themes within their missions than other institutions, but that depth of information was not available in the data set.

Scholars are encouraged to learn more about the specific institutional measures that contribute to students' civic engagement and multicultural competence, as these factors appear to be important in developing students' integrative leadership orientation. In exploring the potential benefits of specific curricular and co-curricular measures, scholars may elicit understanding of the types of measures that can be specifically applied to foster students' development of an integrative leadership orientation. Qualitative research holds the potential to reveal more about institutional and personal factors influencing college students' integrative leadership development. Additional work is also needed to develop and refine future instruments to measure integrative leadership and explore whether integrative leadership orientation is associated with integrative leadership actions put into practice post-graduation.

\section{Conclusion}

The results of this study suggest that higher education's contributions to students' civic engagement and multicultural awareness are positively associated with students' integrative leadership orientation. Higher education institutions that prepare college students for active participation in a diverse democracy are therefore more likely to develop students' ability to work collaboratively to tackle the greatest social challenges of our generation and beyond. Leadership development programs are therefore encouraged to integrate themes of diversity, multiculturalism, civic engagement, and community service into their frameworks, as the inclusion of these themes may enhance college students' integrative leadership orientation. 


\section{References}

Abowitz, K. K., Jayanandhan, S. R., \& Woiteshek, S. (2011). Public and community-based leadership education. In N. V. Longo \& C. M. Gibson (Eds.), From command to community: A new approach to leadership education in colleges and universities (pp. 83102). Medford, MA: Tufts University Press.

ACT. (2010). List of college majors and occupational choices. Iowa City, IA: Author.

Antonio, A. L. (2001). The role of interracial interaction in the development of leadership skills and cultural knowledge and understanding. Research in Higher Education, 42(5), 593617.

Astin, A. W. (1993). What matters in college: Four critical years revisited. San Francisco, CA: Jossey-Bass.

Astin, H. S. (1996). Leadership for social change. About Campus, 1, 4-10.

Astin, A. W., \& Astin, H. S. (2000). Leadership reconsidered: Engaging higher education in social change. Battle Creek, MI: W. K. Kellogg Foundation.

Colby, A., Ehrlich, T., Beaumont, E., \& Stephens, J. (2003). Educating citizens: Preparing America's undergraduates for lives of moral and civic responsibility. San Francisco, CA: Jossey-Bass.

Crosby, B. C., \& Bryson, J. M. (2005). Leadership for the common good: Tackling public problems in a shared world ( $2^{\text {nd }} \mathrm{ed}$.). San Francisco, CA: Jossey-Bass.

Crosby, B. C., \& Bryson, J. M. (2010). Integrative leadership and the creation and maintenance of cross-sector collaborations. The Leadership Quarterly, 21, 211-230.

Dugan, J. P., \& Komives, S. R. (2007). Developing leadership capacity in college students: Findings from a national study. A Report from the Multi-Institutional Study of Leadership. College Park, MD: National Clearinghouse for Leadership Programs.

Dugan, J. P., \& Komives, S. R. (2010). Influences on college students' capacities for socially responsible leadership. Journal of College Student Development, 51(5), 525-549.

Fincher, J., \& Shalka, T. R. (2009). Co-curricular leadership education: Considering critical questions. Journal of Leadership Education, 8(1), 228-237.

Gibson, C. M. \& Longo, N. V. (2011). Defining the new leadership. In N. V. Longo \& C. M. Gibson (Eds.), From command to community: A new approach to leadership education in colleges and universities. (pp. 83-102). Medford, MA: Tufts University Press.

Gurin, P. (1999). Selections from "The Compelling Need for Diversity in Higher Education," Expert reports in defense of the University of Michigan. Equity and Excellence in Higher Education, 32(2), 36-62.

Gurin, P., Dey, E. L., Hurtado, S., \& Gurin, G. (2002). Diversity and higher education: Theory and impact on educational outcomes. Harvard Educational Review, 72(3), 330-366. 
Hartley, M., \& Harkavy, I. (2011). The civic engagement movement and the democratization of the academy. In N. V. Longo \& C. M. Gibson (Eds.), From command to community: A new approach to leadership education in colleges and universities (pp. 83-102). Medford, MA: Tufts University Press.

Heifetz, R., Grashow, A., \& Linsky, M. (2009, July-August). Leadership in a (permanent) crisis. Harvard Business Review, 87(7/8), 62-69.

Hurtado, S. (2001). Linking diversity and educational purpose: How diversity affects the classroom environment and student development. In G. Orfield (Ed.), Diversity challenged: Evidence on the impact of affirmative action (pp. 187-203). Cambridge, MA: Harvard Education Publishing Group and the Civil Rights Project at Harvard University.

Hurtado, S. (2007). Linking diversity with the educational and civic missions of higher education. The Review of Higher Education, 30(2), 185-196.

Hurtado, S., Engberg, M. E., \& Ponjuan, L. (2003, November). The impact of the college experience on students' learning for a diverse democracy. Paper presented at the annual meeting of the Association for the Study of Higher Education. Portland, OR.

Jenkins, D. M. (2012). Exploring signature pedagogies in undergraduate leadership education. Journal of Leadership Education, 11(1), 1-27.

King, P. M. (1997). Character and civic education: What does it take? The Educational Record, 78(3-4), 87-93.

Komives, S. R., Lucas, N., \& McMahon, T. R. (2006). Exploring leadership: For college students who want to make a difference ( $2^{\text {nd }} \mathrm{Ed}$.). San Francisco, CA: Jossey-Bass.

Komives, S. R., Wagner, W., \& Associates. (2009). Leadership for a better world: Understanding the social change model of leadership development. San Francisco, CA: Jossey-Bass.

Mitchell, T. D. (2008). Traditional vs. critical service-learning: Engaging the literature to differentiate two models. Michigan Journal of Community Service Learning, 14(2), 5065.

Mitchell, T. D., Keene, A., \& Battistoni, R. (2011). Educating for democratic leadership at Stanford, UMass, and Providence College. In N. V. Longo \& C. M. Gibson (Eds.), From command to community: A new approach to leadership education in colleges and universities (pp. 83-102). Medford, MA: Tufts University Press.

Morse, R. S. (2010). Integrative public leadership: Catalyzing collaboration to create public value. The Leadership Quarterly, 21, 231-245.

Page, S. (2010). Integrative leadership for collaborative governance: Civic engagement in Seattle. The Leadership Quarterly, 21, 246-263. 
Schneider, C. G. (2005). Liberal education: Slip-sliding away? In R. H. Hersh \& J. Merrow (Eds.), Declining by degrees: Higher education at risk (pp. 61-76). New York, NY: Palgrave Macmillon.

Silvia, C., \& McGuire, M. (2010). Leading public sector networks: An empirical examination of integrative leadership behaviors. The Leadership Quarterly, 21, 264-277.

Soria, K. M., Fink, A., Lepkowski, C. C., \& Snyder, L. (2013). Undergraduate student leadership and social change. Journal of College and Character, 14(3), 241-252.

Soria, K. M., \& Johnson, M. (2013, November). Preparing future citizens and leaders by developing college students' multicultural competence. Association for the Study of Higher Education, St. Louis, MO.

Soria, K. M., Nobbe, J., \& Fink, A. (2013). Examining the intersections between undergraduates' engagement in community service and development of socially responsible leadership. Journal of Leadership Education, 12(1), 117-140.

Sun, P. Y. T., Anderson, M. H. (2012). Civic capacity: Building on transformational leadership to explain integrative public leadership. The Leadership Quarterly, 23, 309-323.

Van Wart, M. (2008). Leadership in public organizations: An introduction. Armonk, NY: M. E. Sharpe.

Whitt, E. J., Edison, M. I., Pascarella, E. T., Terenzini, P. T., \& Nora, A. (2001). Influences on students' openness to diversity and challenge in the second and third years of college.

The Journal of Higher Education, 72(2), 172-204.

Williams, P. (2002). The competent boundary spanner. Public Administration, 80(1), 103-124.

Zimmerman-Oster, K., \& Burkhardt, J. C. (1999). Leadership in the making: Impact and insights from leadership development programs in U.S. colleges and universities. Battle Creek,

MI: W. K. Kellogg Foundation.

Zuniga, X., Williams, E. A., \& Berger, J. B. (2005). Action-oriented democratic outcomes: The impact of student involvement with campus diversity. Journal of College Student

Development, 46(6), 660-678.

\section{Author Biographies}

Dr. Krista M. Soria is an analyst with the Office of Institutional Research and an adjunct faculty in the leadership minor at the University of Minnesota. Dr. Soria's research interests include undergraduate students' leadership development, the experiences of first-generation and working-class students in higher education, and the effects of high-impact practices in higher education. 
Seth C. Snyder is a doctoral student in the College of Education and Human Development at the University of Minnesota, focusing on organizational leadership, policy, \& development in higher education. His research interests include first-generation student success, student leadership development, multicultural education, and multi-ethnic identity development. He earned an M.A. from Stanford University in international and comparative education, with a focus on higher education.

Alex P. Reinhard is an undergraduate student in the College of Education and Human Development at the University of Minnesota, majoring in business and marketing and minoring in both leadership and management. Alex's current focus is on applying his ten years of business experience towards completing his bachelor's degree, with the goal of pursuing an MBA degree. $\mathrm{He}$ is interested in exploring ways that undergraduate business students can learn and develop leadership skills that will strongly translate into the professional world. 